\title{
The immune response of stem cells in subretinal transplantation
}

\author{
Bikun Xian and Bing Huang ${ }^{*}$
}

\begin{abstract}
Stem cell transplantation is a potential curative treatment for degenerative diseases of the retina. Among cell injection sites, the subretinal space (SRS) is particularly advantageous as it is maintained as an immune privileged site by the retinal pigment epithelium (RPE) layer. Thus, the success of subretinal transplantation depends on maintenance of RPE integrity. Moreover, both embryonic stem cells (ESCS) and mesenchymal stem cells (MSCs) have negligible immunogenicity and in fact are immunosuppressive. Indeed, many studies have demonstrated that immunosuppressive drugs are not necessary for subretinal transplantation of stem cells if the blood-retinal barrier is not breached during surgery. The immunogenicity of induced pluripotent stem cells (iPSCs) appears more complex, and requires careful study before clinical application. Despite low rates of graft rejection in animal models, survival rates for ESCS, MSCs, and $\mathrm{PPSC}$ in retina are generally poor, possibly due to resident microglia activated by cell transplantation. To improve graft survival in SRS transplantation, damage to the blood-retinal barrier must be minimized using appropriate surgical techniques. In addition, agents that inhibit microglial activation may be required. Finally, immunosuppressants may be required, at least temporarily, until the blood-retinal barrier heals. We review surgical methods and drug regimens to enhance the likelihood of graft survival after SRS transplantation.
\end{abstract}

\section{Introduction}

Retinal degenerative diseases such as age-related macular degeneration and retinitis pigmentosa are characterized by irreversible loss of retinal pigment epithelium (RPE) cells, photoreceptors, choriocapillaries, and other retinal cells [1]. These degenerative diseases afflict millions of people

\footnotetext{
* Correspondence: huangbing2000@hotmail.com

State Key Laboratory of Ophthalmology, Zhongshan Ophthalmic Center, Sun Yat-sen University, Guangzhou 510060Guangdong Province, China
}

worldwide but there are currently no broadly effective treatments for them. Stem cell-based therapy is a potential approach for the treatment of retinal degenerative diseases [2-7], and many animal studies [8-15] and some clinical trials [16-18] have indeed shown encouraging results.

Stem cells have the capacity for both self-renewal and differentiation into multiple cell lineages (pluripotency) [19]. They also have low immunogenicity [20, 21], reducing the chance of rejection. Moreover, the subretinal space (SRS) is an immunoprivileged site within the eye [22] and thus a logical target for cell transplantation. In fact, grafts transplanted into the SRS have shown better migration and integration than cells transplanted into the vitreous cavity [23, 24]. Transplantation of lowimmunogenicity cells into this immunoprivileged site appears particularly promising, although most studies using stem cells for SRS transplantation have observed poor survival. Successful transplantation thus requires more detailed knowledge of how the host immune system responds to SRS stem cell transplantation. In this review, we discuss the immune characteristics of the SRS and of various stem cells, and their interaction after transplantation. We then summarize methods that can suppress the immune response of the host and improve graft survival.

\section{Immune privilege of the subretinal space}

The SRS is the area between the RPE layer and the outer limiting membrane of the retina. The RPE is critical for the immunoprivileged status of the SRS. Sugita et al. [25] found that RPE cells in vitro can suppress T-cell activation by direct cell-to-cell contact, and Zamiri and colleagues [26] reported that just the supernatant of the RPE eyecup suppressed T-cell activation and production of interferon. Wenkel and Streilein [27] reported that the SRS suppressed cell-associated and soluble antigenspecific delayed-type hypersensitivity. Moreover, they found that the immune privilege of the SRS was dependent on the presence of an intact and healthy RPE cell monolayer. The mechanisms conferring immune 
privilege include (1) suppression of T-cell activation by release of cytokines from the RPE, such as transforming growth factor- $\beta$ [28], thrombospondin-1 [29], prostaglandin E2 [25], cytotoxic T lymphocyte associated antigen- $2 \alpha$ [30], and retinoic acid [31]; (2) production of other immunosuppressive factors by RPE cells that suppress innate immune activity, including pigment epithelium-derived factor and somatostatin [32]; (3) surface expression of program death-1 (PD-L1) [33] and Fas ligand [34] by RPE cells; (4) conversion of CD8+ and CD4+ T cells into regulatory T cells [30]; and (5) the intact physical barrier of the RPE layer [27].

\section{The immunogenicity of stem cells}

Stem cells hold great promise for regenerative medicine due to their pluripotency and capacity for selfrenewal. As one of the most important characteristics of a potential cell for grafting, immunogenicity has been extensively researched. Yuan et al. [35] reported that embryonic stem cells (ESCs) and their derivatives escaped host immune attack and survived for long periods in animal models. There are at least three reasons for this low immunogenicity. First, human ESCs express low levels of human leukocyte antigen (HLA) class I molecules and do not express HLA class II molecules in either the resting or differentiated state [36, 37]. Second, ESCs lack co-stimulatory molecules, such as CD80 and CD86 [38]. Third, ESCs suppress naive and dendritic cell-mediated T-cell proliferation in allogeneic settings [39]. Like ESCs, mesenchymal stem cells (MSCs) also have negligible immunogenicity and the capacity for immune suppression. MSCs express low levels of major histocompatibility complex (MHC) class I molecules but lack expression of MHC class II molecules and the costimulary molecules CD80, CD86, and CD40 [40-42]. In addition, MSCs inhibit dendritic cells [43-45], T cells $[46,47]$, B cells [48], natural killer cells $[49,50]$, and macrophages [51]. Contrary to expectation, however, some studies have found that induced pluripotent stem cells (iPSCs) derived from autologous cells are rejected by the recipient.

Zhao and colleagues [52] reported that, after reprogramming, iPSCs expressed high levels of Zg16 and Hormad, which led to immunogenicity. Moreover, the teratomas formed by these iPSCs were rejected by the recipient after syngeneic subcutaneous transplantation. In contrast, Guha et al. [53] found no correlation between the expression of Zg16 and Hormad and the survival of syngeneic iPSCs grafts, as neither undifferentiated syngeneic iPSCs nor differentiated cells derived from them were rejected after subrenal capsule transplantation. Similarly, Araki et al. [20] reported that iPSCs were no more immunogenic than ESCs. To explain this contradiction, Kaneko and Yamanaka speculated that variation in immune response may be due to the different iPSCs lines and vectors used for reprogramming [54]. The iPSCs with strong immunogenicity reported by Zhao et al. [52] were derived with retroviruses. Retroviral vectors can change host gene expression by integrating at transcriptional sites, resulting in the abnormal production of immunogenic proteins. Kaneko and Yamanaka thus suggested that retroviral vectors should not be used to generate iPSCs for transplantation therapy [54]. Alternatively, $\mathrm{Fu}$ [55] suggested that, compared with cells grafted into the subrenal capsule, cells grafted subcutaneously are exposed to more functional dendritic cells (such as Langerhans cells). Therefore, even cells with immunogenicity in other tissues (like iPSCs transformed using retroviral vectors) may not induce rejection when injected into the subrenal capsule. Thus, the subrenal capsule may not be an appropriate site for studying the immune response to minor antigens in preclinical studies. Cao et al. [56] speculated that iPSCs could acquire genetic and/or epigenetic defects after reprogramming, thereby generating immunogenicity. As not all descendants of iPSCs express the defects during development and differentiation, however, autologous iPSCs could show much weaker immunogenicity than allografts. If they expressed immunogenic minor antigens anomalously, however, they still could elicit immune rejection [56]. Hence, the potential immunogenicity of each iPSC-derived cell line should be tested carefully before clinical application.

\section{Studies of immune rejection after subretinal transplantation}

In the majority of instances, donor cells survive SRS transplantation without immunosuppressive drugs. We analyzed a myriad of studies [57-70] focused on the immune reaction and/or using immunosuppressive drugs. Findings can be summarized as follows. First, none of the hosts administered immunosuppressive drugs showed immune rejection during the observation period, suggesting that immunosuppressants are effective for prevention of immune rejection of grafts within the SRS. Second, only three studies reported classic rejection at the transplant site. One found disruption of the host RPE layer at the transplant site [64], one used laser burn [60], and one used diathermy [58] during surgery, and none applied postoperative immunosuppression. Although laser application promoted migration and integration of donor cells into host retina [71], it led to focal injury of the RPE and likely breached the blood-retinal barrier, implying that the integrity of the blood-retinal barrier also plays an important role in graft preservation. Lu and colleagues [67] provided further evidence that maintenance of blood-retinal barrier integrity, rather than immunosuppression, is the critical factor for preventing rejection following SRS transplantation. In 
their study, they excluded eyes with a damaged blood-retinal barrier after subretinal injection and found no statistical difference in rejection rate between the immunosuppressortreated group and the no immunosuppressor group. Indeed, both groups achieved therapeutic benefits from transplantation without immunological rejection. These observations collectively demonstrate that if the bloodretinal barrier is preserved during surgery, immunosuppressive drugs are not necessary. Note also that several of the studies used rabbits as recipients, all receiving postoperative immunosuppression. While no immune rejection was reported, the survival of the grafts was generally poor [63-65]. This may be associated with the unique retinal anatomy of rabbits. Compared with holangiotic species such as humans and rats, the rabbit retina is merangiotic [72], meaning that only part of the inner retina is supplied by retinal vessels and is more dependent, therefore, on choriocapillaries, while humans and rats possess a retinal vasculature that penetrates throughout the inner retina. Thus, the rabbit may not be the best candidate for animal investigations of retinal cell therapy.

\section{Surgical methods used in subretinal transplantation}

A variety of surgical techniques have been developed to allow efficient SRS transplantation while protecting the blood-retinal barrier. For rodents with small eyes (rats and mice), scleral incision by a needle or blade is followed by stem cell injection through a syringe. In order to prevent reflux and improve the survival of cell grafts, several studies have used corneal puncture, which also reduces intraocular pressure. Some groups have kept the needle in the injection site for a few seconds then pulled it out slowly to maximize cell delivery to the SRS and minimize the potential for damage [73], and another created a self-sealing sclerotomy [74]. For subjects with larger eyes, such as rabbits, pigs, monkeys, and humans, an initial posterior pars plana vitrectomy has been performed to induce posterior vitreous detachment, then a syringe used to deliver the grafted cells. We suggest that the vitrectomy can reduce cell reflux and intraocular pressure. While cells are usually injected as a suspension, some groups have created new approaches to cell delivery. Kamao et al. [58] generated monolayer cell sheets without scaffolds using collagen gel and collagenase, while Stanzel et al. [63] and Hu et al. [75] cultured and maintained seed cells on polyester membranes and parylene substrates, respectively. In all these studies, cells were transplanted as a layered structure rather than as a suspension. Kundu et al. [76] demonstrated that suspended cells injected in the SRS could integrate into the host retina, but survival was poor due to loss of cells by reflux, while cell layer transplantation allowed for greater cell retention. If cell layers are transplanted, any scaffold used must be biocompatible and non-immunogenic but strong and flexible enough to withstand surgical manipulation [76].

However, all current clinical trials registered by the US National Institutes of Health use suspended cells for subretinal transplantation. Most use MA09-hRPE cells, which are fully differentiated from human ESCs, while one is using OpRegen cells, which are RPE cells derived from human ESCs (NCT02286089). Two groups are using human central nervous system stem cells (NCT01632527, NCT02137915), another team human retinal progenitor cells (NCT02464436), and another autologous bone marrow-derived stem cells (NCT01920867). In Japan (RIKEN), iPSCs are currently being used in clinical trials to treat age-related macular degeneration.

\section{Microglial activation in the retina following stem cell transplant}

While most studies have found no evidence of graft rejection, such as leakage of fluorescein on fluorescein angiography or immune cell infiltration at transplantation sites, long-term graft survival rates are often poor. This poor survival is a major hindrance to clinical application and has thus received extensive experimental attention. Singhal et al. [77] observed substantial microglial accumulation at the site of cell injection, which inhibited Müller stem cell migration, and Bull et al. [78] reported that, in spite of an immunosuppressive regimen, Müller stem cells transplanted into the vitreous or SRS were eventually rejected due to attack by microglia/ macrophages.

Microglia are the resident cells mediating innate immunity in the retina. There are two distinct microglial populations: the perivascular macrophages situated within the glial limitans of the inner retinal vasculature and the ramified retinal microglia within the tissue parenchyma $[79,80]$. In the developing human retina, microglia are present in the developing nerve fiber as well as the ganglion cell, inner plexiform, and outer plexiform layers [81]. Ramified microglial cells are characterized by small, slender cell bodies, with long, radial, and highly dynamic protrusions [82]. This special morphology allows the entire microglia population to cover every part of the retina and contribute to tissue homeostasis without activation [83]. However, the situation changes when microglia are activated by nerve degeneration [82], inflammation [84, 85], traumatic nerve lesion [86], or excessive light overexposure [87]. Activated microglia show directed polarity and rapidly migrate toward the region of damage. In the activated state, they have dual capacity to modulate neurogenesis, both by enhancing progenitor cell proliferation and by inhibiting neurosphere generation and the extent of differentiation [88]. Activated microglia also exert complex effects on immunity and cell survival by secreting various cytokines, such as interleukin (IL)-1 $\beta$, IL-10, 
tumor necrosis factor (TNF)- $\alpha$, and IL-6 [89]. While IL-10 is generally considered anti-inflammatory, immunosuppressive, and neuroprotective [90], IL-1 $\beta$, IL-6, and TNF- $\alpha$ are pro-inflammatory and neurotoxic [84].

\section{Treatments for moderating microglial activation}

Endogenous glucocorticoids, such as triamcinolone, prednisolone, and dexamethasone, are well known suppressors of the innate immune response [91]. Glucocorticoids can suppress cytokine-mediated microglia proliferation [92] and accumulation [93], and downregulate cytotoxic molecules such as nitric oxide [94], TNF, IL-6 [95], and glutamate [96]. Singhal et al. [93] reported that the survival of transplanted cells was significantly enhanced by triamcinolone. The novel resveratrol analogue RV09 (5-[2-(4-bromothiophen-2-yl)vinyl]benzene-1,3-diol) can also control microglial activation and cytotoxicity. Meng et al. [97] found that RV09 inhibited lipopolysaccharide-induced nitric oxide and TNF- $\alpha$ production in microglia. In addition to glucocorticoids and RV09, minocycline suppressed microglial activation [98-101] and prevented neuronal loss by inhibiting inducible nitric oxide synthase induction [102], caspase expression [103], and cytochrome c release [104]. However, while $10 \mu \mathrm{g} / \mathrm{ml}$ or lower did not affect neural progenitor cell (NPC) survival and proliferation, higher minocycline concentrations (20 and $40 \mu \mathrm{g} / \mathrm{ml}) \mathrm{im}$ paired NPC differentiation in culture [105].

\section{Effective ways to improve graft survival following subretinal transplantation}

The studies cited above suggest several ways to mitigate the immune response following transplantation. The most important is to improve surgical skills and procedures to maintain blood-retinal barrier integrity. Drugs such as glucocorticoids, RV09, and minocycline that can inhibit proliferation and activation of microglia are also beneficial. If the blood-retinal barrier is ruptured during surgery, immunosuppressive drugs such as cyclosporine A may be necessary. However, these agents should be used with caution. Skardelly et al. [106] found that even at the minimum effective concentrations, all immunosuppressants tested (cyclosporine A, everolimus, mycophenolic acid, and prednisolone) reduced the proliferative capacity of human NPCs, especially cyclosporine A and mycophenolic acid, and altered their NAD(P)H-dependent metabolic activity. Moreover, mycophenolic acid treatment induced apoptotic death. Alternatively, cell death rate, neurogenesis, gliogenesis, and cell migration were unaffected by these agents. Rota et al. [107] suggested that transient immunosuppression was sufficient for long-term survival of human NPCs and engraftment. Wenkel et al. [27] also found that the blood-retinal barrier was fully reformed 21 days after intravenous injection of sodium iodate. Hence, to reduce the side effects of traditional immunosuppressants, drugs can be withdrawn after a month. Additionally, injection of grafts combined with chondroitinase $\mathrm{ABC}$ caused a dramatic increase in the migration of Müller stem cells into all retinal cell layers [77] and improved synapse formation of transplanted photoreceptor precursors with host neurons [108]. This may be explained by the repression of synaptogenesis [109], stem cell migration, and integration into the damaged retina by microglial deposition of chondroitin sulfate proteoglycans. More specific immunosuppressive strategies have also been developed to improve graft survival. Pearl et al. [110] show that blocking leukocyte co-stimulatory molecules, such as cytotoxic T-lymphocyte-associated antigen 4 (CTLA4-Ig), antiCD40 ligand, and anti-lymphocyte function-associated antigen 1, permitted long-term engraftment of allogeneic ESCs, mitigated xenogeneic immune rejection of both undifferentiated and in vivo differentiated ESCs, and prevented rejection following allogeneic and xenogeneic transplantation of iPSCs. Rong et al. [111] established knock-in human ESCs constitutively expressing CTLA4-Ig and PD-L1 before and after differentiation, and showed that human ESC-derived allografts could be implanted without the need for systemic immune suppression.

\section{Conclusion}

Although both the SRS and stem cells have low immunogenicity, therapeutic stem cells in various states of differentiation and delivered via different transplantation protocols show distinctive survival, differentiation, and migration capacities in the host. First, cell survival after transplantation depends on technical aspects of graft preparation, including the harvesting technique, cell purity, and tissue storage methods. Second, the state of the host also influences transplant success, as better migration and integration of stem cells have been observed when neural progenitors are transplanted into immature or injured retina [112-114]. The anatomy of the retina also influences the survival of the graft, so host species is important for experimental studies and clinical translation. Appropriate surgical methods are also paramount. Cells injected into the SRS migrate in the retina better than cells injected into the vitreous cavity. Anterior chamber paracentesis or vitrectomy can prevent graft leakage and mitigate excessive intraocular pressure during surgery. Chondroitinase $\mathrm{ABC}$ can be used to increase the migration of stem cells into all retinal cell layers. Postoperational treatment also influences graft survival. As microglia are activated after transplantation, anti-microglial drugs could be of great benefit. When the blood-retinal barrier is broken, immunosuppressants are needed, at least until the barrier has reformed. These drugs should be withdrawn as early as 


\section{possible, however, to mitigate suppressive effects of these agents on cell survival, proliferation, and/or migration.}

\section{Abbreviations}

CTLA4-Ig: Cytotoxic T-lymphocyte-associated antigen 4; ESC: Embryonic stem cell; HLA: Human leukocyte antigen; IL-1: Interleukin; iPSC: Induced pluripotent stem cell; MHC: Major histocompatibility complex; MSC: Mesenchymal stem cell; NPC: Neural progenitor cell; PD-L1: Program death-1; RPE: Retinal pigment epithelium; RV09: 5-[2-(4-bromothiophen-2-yl)vinyl]benzene-1,3-diol; SRS: Subretinal space; TNF: Tumor necrosis factor.

\section{Competing interests}

The authors declare that they have no competing interests.

\section{Acknowledgments}

We are grateful for financial support from the Science and Technology Projects of Guangdong Province, China (2013B040200020, 2013B060300003) and the fundamental research fund of State Key Laboratory of Ophthalmology of China (2012P105).

\section{Published online: 14 September 2015}

\section{References}

1. Kolomeyer AM, Zarbin MA. Trophic factors in the pathogenesis and therapy for retinal degenerative diseases. Surv Ophthalmol. 2014;59:134-65.

2. Yu H, Vu TH, Cho KS, Guo C, Chen DF. Mobilizing endogenous stem cells for retinal repair. Transl Res. 2014;163:387-98.

3. Zhang $Y$, Luo $Y$, Li K, Zhang $M$, Huang B, Peng $Y$, et al. Pre-induced adult human peripheral blood mononuclear cells migrate widely into the degenerative retinas of rd1 mice. Cytotherapy. 2013:15:1416-25.

4. Lewallen M, Xie T. Cell-based therapies for retinal degenerative diseases: a thousand strategies. J Glaucoma. 2013;22:S42-5.

5. Wong IY, Poon MW, Pang RT, Lian Q, Wong D. Promises of stem cell therapy for retinal degenerative diseases. Graefes Arch Clin Exp Ophthalmol. 2011;249:1439-48.

6. Huang Y, Enzmann V, Ildstad ST. Stem cell-based therapeutic applications in retinal degenerative diseases. Stem Cell Rev. 2011;7:434-45.

7. Dhamodaran K, Subramani M, Ponnalagu M, Shetty R, Das D. Ocular stem cells: a status update! Stem Cell Res Ther. 2014;5:56

8. Reichman S, Goureau O. Production of retinal cells from confluent human iPS cells. Methods Mol Biol. 2014. doi:10.1007/7651_2014_143.

9. Assawachananont J, Mandai M, Okamoto S, Yamada C, Eiraku M, Yonemura $S$, et al. Transplantation of embryonic and induced pluripotent stem cellderived $3 \mathrm{~d}$ retinal sheets into retinal degenerative mice. Stem Cell Reports. 2014:2:662-74

10. Nadri S, Kazemi B, Eslaminejad MB, Yazdani S, Soleimani M. High yield of cells committed to the photoreceptor-like cells from conjunctiva mesenchymal stem cells on nanofibrous scaffolds. Mol Biol Rep. 2013;40:3883-90.

11. Decembrini S, Koch U, Radtke F, Moulin A, Arsenijevic Y. Derivation of traceable and transplantable photoreceptors from mouse embryonic stem cells. Stem Cell Reports. 2014;2:853-65.

12. Duan $P, X u H$, Zeng $Y$, Wang $Y, Y$ in $Z Q$. Human bone marrow stromal cells can differentiate to a retinal pigment epithelial phenotype when co-cultured with pig retinal pigment epithelium using a transwell system. Cell Physiol Biochem. 2013;31:601-13.

13. Kanno $\mathrm{H}$. Regenerative therapy for neuronal diseases with transplantation of somatic stem cells. World J Stem Cells. 2013;5:163-71.

14. Hartmann K, Raabe O, Wenisch S, Arnhold S. Amniotic fluid derived stem cells give rise to neuron-like cells without a further differentiation potential into retina-like cells. Am J Stem Cells. 2013;2:108-18.

15. Peng $Y$, Zhang $Y$, Huang $B$, Luo $Y$, Zhang M, Li K, et al. Survival and migration of pre-induced adult human peripheral blood mononuclear cells in retinal degeneration slow (rds) mice three months after subretinal transplantation. Curr Stem Cell Res Ther. 2014;9:124-33.

16. Schwartz SD, Hubschman JP, Heilwell G, Franco-Cardenas V, Pan CK, Ostrick $\mathrm{RM}$, et al. Embryonic stem cell trials for macular degeneration: a preliminary report. Lancet. 2012;379:713-20.
17. Schwartz SD, Regillo CD, Lam BL, Eliott D, Rosenfeld PJ, Gregori NZ, et al. Human embryonic stem cell-derived retinal pigment epithelium in patients with age-related macular degeneration and Stargardt's macular dystrophy: follow-up of two open-label phase 1/2 studies. Lancet. 2015;385:509-16.

18. Song WK, Park KM, Kim HJ, Lee JH, Choi J, Chong SY, et al. Treatment of macular degeneration using embryonic stem cell-derived retinal pigment epithelium: preliminary results in Asian patients. Stem Cell Reports. 2015;4:860-72.

19. Cheung TH, Rando TA. Molecular regulation of stem cell quiescence. Nat Rev Mol Cell Biol. 2013;14:329-40.

20. Araki R, Uda M, Hoki Y, Sunayama M, Nakamura M, Ando S, et al. Negligible immunogenicity of terminally differentiated cells derived from induced pluripotent or embryonic stem cells. Nature. 2013;494:100-4.

21. Wu KH, Wu HP, Chan CK, Hwang SM, Peng CT, Chao YH. The role of mesenchymal stem cells in hematopoietic stem cell transplantation: from bench to bedsides. Cell Transplant. 2013;22:723-9.

22. Zamiri P, Sugita S, Streilein JW. Immunosuppressive properties of the pigmented epithelial cells and the subretinal space. Chem Immunol Allergy. 2007;92:86-93.

23. Tzameret A, Sher I, Belkin M, Treves AJ, Meir A, Nagler A, et al. Transplantation of human bone marrow mesenchymal stem cells as a thin subretinal layer ameliorates retinal degeneration in a rat model of retinal dystrophy. Exp Eye Res. 2014;118:135-44.

24. Sauve Y, Klassen H, Whiteley SJ, Lund RD. Visual field loss in RCS rats and the effect of RPE cell transplantation. Exp Neurol. 1998;152:243-50.

25. Sugita S, Futagami Y, Smith SB, Naggar H, Mochizuki M. Retinal and ciliary body pigment epithelium suppress activation of T lymphocytes via transforming growth factor beta. Exp Eye Res. 2006;83:1459-71.

26. Zamiri P, Masli S, Kitaichi N, Taylor AW, Streilein JW. Thrombospondin plays a vital role in the immune privilege of the eye. Invest Ophthalmol Vis Sci. 2005;46:908-19.

27. Wenkel H, Streilein JW. Analysis of immune deviation elicited by antigens injected into the subretinal space. Invest Ophthalmol Vis Sci. 1998;39:1823-34

28. Sugita S, Horie S, Nakamura O, Maruyama K, Takase H, Usui Y, et al. Acquisition of $T$ regulatory function in cathepsin L-inhibited $T$ cells by eye-derived CTLA-2alpha during inflammatory conditions. J Immunol. 2009:183:5013-22.

29. Futagami Y, Sugita S, Vega J, Ishida K, Takase H, Maruyama K, et al. Role of thrombospondin-1 in T cell response to ocular pigment epithelial cells. J Immunol. 2007;178:6994-7005.

30. Sugita S, Horie S, Nakamura O, Futagami Y, Takase H, Keino H, et al. Retinal pigment epithelium-derived CTLA-2alpha induces TGFbeta-producing T regulatory cells. J Immunol. 2008;181:7525-36.

31. Kawazoe Y, Sugita S, Keino H, Yamada Y, Imai A, Horie S, et al. Retinoic acid from retinal pigment epithelium induces $T$ regulatory cells. Exp Eye Res. 2012;94:32-40.

32. Zamiri P, Masli S, Streilein JW, Taylor AW. Pigment epithelial growth factor suppresses inflammation by modulating macrophage activation. Invest Ophth Vis Sci. 2006;47:3912-8.

33. Sugita S, Usui Y, Horie S, Futagami Y, Aburatani H, Okazaki T, et al. T-cell suppression by programmed cell death 1 ligand 1 on retinal pigment epithelium during inflammatory conditions. Invest Ophthalmol Vis Sci. 2009;50:2862-70.

34. Ferguson TA, Griffith TS. The role of Fas ligand and TNF-related apoptosisinducing ligand (TRAIL) in the ocular immune response. Chem Immunol Allergy. 2007;92:140-54.

35. Yuan $X$, Zhang H, Wei Y, Hu S. Embryonic stem cell transplantation for the treatment of myocardial infarction: immune privilege or rejection. Transpl Immunol. 2007;18:88-93.

36. Drukker M, Katz G, Urbach A, Schuldiner M, Markel G, Itskovitz-Eldor J, et al. Characterization of the expression of $\mathrm{MHC}$ proteins in human embryonic stem cells. Proc Natl Acad Sci U S A. 2002;99:9864-9.

37. Boyd AS, Higashi Y, Wood KJ. Transplanting stem cells: potential targets for immune attack. Modulating the immune response against embryonic stem cell transplantation. Adv Drug Deliver Rev. 2005;57:1944-69.

38. Drukker M, Katchman H, Katz G, Even-Tov Friedman S, Shezen E, Hornstein E, et al. Human embryonic stem cells and their differentiated derivatives are less susceptible to immune rejection than adult cells. Stem Cells. 2006;24:221-9.

39. Li L, Baroja ML, Majumdar A, Chadwick K, Rouleau A, Gallacher L, et al. Human embryonic stem cells possess immune-privileged properties. Stem Cells. 2004;22:448-56. 
40. Jacobs SA, Roobrouck VD, Verfaillie CM, Van Gool SW. Immunological characteristics of human mesenchymal stem cells and multipotent adult progenitor cells. Immunol Cell Biol. 2013;91:32-9.

41. Han KH, Kang HG, Gil HJ, Lee EM, Ahn C, Yang J. The immunosuppressive effect of embryonic stem cells and mesenchymal stem cells on both primary and secondary alloimmune responses. Transpl Immunol. 2010;23:141-6.

42. Krampera $M$, Cosmi L, Angeli R, Pasini A, Liotta F, Andreini A, et al. Role for interferon- $\gamma$ in the immunomodulatory activity of human bone marrow mesenchymal stem cells. Stem Cells. 2006;24:386-98.

43. Zhang W, Ge W, Li C, You S, Liao L, Han Q, et al. Effects of mesenchymal stem cells on differentiation, maturation, and function of human monocytederived dendritic cells. Stem Cells Dev. 2004;13:263-71.

44. Jiang XX, Zhang $Y$, Liu B, Zhang SX, Wu Y, Yu XD, et al. Human mesenchymal stem cells inhibit differentiation and function of monocyte-derived dendritic cells. Blood. 2005;105:4120-6.

45. Abomaray FM, Al JM, Kalionis B, AlAskar AS, Al HS, Jawdat D, et al. Human chorionic villous mesenchymal stem cells modify the functions of human dendritic cells, and induce an anti-inflammatory phenotype in CD1+ dendritic cells. Stem Cell Rev. 2014. doi:10.1007/s12015-014-9562-8.

46. Bartholomew A, Sturgeon C, Siatskas M, Ferrer K, McIntosh K, Patil S, et al. Mesenchymal stem cells suppress lymphocyte proliferation in vitro and prolong skin graft survival in vivo. Exp Hematol. 2002;30:42-8.

47. Di Nicola M, Carlo-Stella C, Magni M, Milanesi M, Longoni PD, Matteucci P, et al. Human bone marrow stromal cells suppress T-lymphocyte proliferation induced by cellular or nonspecific mitogenic stimuli. Blood. 2002;99:3838-43.

48. Corcione A, Benvenuto F, Ferretti E, Giunti D, Cappiello V, Cazzanti F, et al. Human mesenchymal stem cells modulate B-cell functions. Blood. 2006;107:367-72.

49. Sordi V, Piemonti L. Therapeutic plasticity of stem cells and allograft tolerance. Cytotherapy. 2011;13:647-60.

50. Ribeiro A, Laranjeira P, Mendes S, Velada I, Leite C, Andrade P, et al. Mesenchymal stem cells from umbilical cord matrix, adipose tissue and bone marrow exhibit different capability to suppress peripheral blood B, natural killer and T cells. Stem Cell Res Ther. 2013;4:125.

51. Abumaree $\mathrm{MH}, \mathrm{Al} \mathrm{JM}$, Kalionis $\mathrm{B}$, Jawdat $\mathrm{D}, \mathrm{Al}$ KA, Abomaray FM, et al. Human placental mesenchymal stem cells (pMSCs) play a role as immune suppressive cells by shifting macrophage differentiation from inflammatory M1 to anti-inflammatory M2 macrophages. Stem Cell Rev. 2013:9:620-41.

52. Zhao T, Zhang Z, Rong Z, Xu Y. Immunogenicity of induced pluripotent stem cells. Nature. 2011:474:212-5.

53. Guha P, Morgan JW, Mostoslavsky G, Rodrigues NP, Boyd AS. Lack of immune response to differentiated cells derived from syngeneic induced pluripotent stem cells. Cell Stem Cell. 2013;12:407-12.

54. Kaneko S, Yamanaka S. To be immunogenic, or not to be: that's the iPSC question. Cell Stem Cell. 2013;12:385-6.

55. Fu X. The immunogenicity of cells derived from induced pluripotent stem cells. Cell Mol Immunol. 2013;11:14-6.

56. Cao J, Li X, Lu X, Zhang C, Yu H, Zhao T. Cells derived from iPSC can be immunogenic - yes or no? Protein Cell. 2014;5:1-3.

57. del Cerro M, Humayun MS, Sadda SR, Cao J, Hayashi N, Green WR, et al. Histologic correlation of human neural retinal transplantation. Invest Ophthalmol Vis Sci. 2000;41:3142-8.

58. Kamao H, Mandai M, Okamoto S, Sakai N, Suga A, Sugita S, et al. Characterization of human induced pluripotent stem cell-derived retinal pigment epithelium cell sheets aiming for clinical application. Stem Cell Reports. 2014;2:205-18.

59. Francis PJ, Wang S, Zhang Y, Brown A, Hwang T, McFarland TJ, et al. Subretinal transplantation of forebrain progenitor cells in nonhuman primates: survival and intact retinal function. Invest Ophth Vis Sci. 2009;50:3425-31

60. Warfvinge $\mathrm{K}$, Schwartz PH, Kiilgaard JF, la Cour M, Young MJ, Scherfig E, et al. Xenotransplantation of human neural progenitor cells to the subretinal space of nonimmunosuppressed pigs. J Transplant. 2011;2011:1-6.

61. Warfvinge K, Kiilgaard JF, Klassen H, Zamiri P, Scherfig E, Streilein W, et al. Retinal progenitor cell xenografts to the pig retina: immunological reactions. Cell Transplant. 2006;15:603-12.

62. Klassen H, Kiilgaard JF, Zahir T, Ziaeian B, Kirov I, Scherfig E, et al. Progenitor cells from the porcine neural retina express photoreceptor markers after transplantation to the subretinal space of allorecipients. Stem Cells. 2007;25:1222-30.
63. Stanzel BV, Liu Z, Somboonthanakij S, Wongsawad W, Brinken R, Eter N, et al. Human RPE stem cells grown into polarized RPE monolayers on a polyester matrix are maintained after grafting into rabbit subretinal space. Stem Cell Reports. 2014;2:64-77.

64. Lai CC, Gouras P, Doi K, Tsang SH, Goff SP, Ashton P. Local immunosuppression prolongs survival of RPE xenografts labeled by retroviral gene transfer. Invest Ophthalmol Vis Sci. 2000;41:3134-41.

65. Del PL, Ishida O, Johnson EW, Sheng Y, Jacoby DB, Geng L, et al. Triple immune suppression increases short-term survival of porcine fetal retinal pigment epithelium xenografts. Invest Ophthalmol Vis Sci. 2003;44:4044-53.

66. Banin E, Obolensky A, Idelson M, Hemo I, Reinhardtz E, Pikarsky E, et al. Retinal incorporation and differentiation of neural precursors derived from human embryonic stem cells. Stem Cells. 2006;24:246-57.

67. Lu B, Wang S, Girman S, McGill T, Ragaglia V, Lund R. Human adult bone marrow-derived somatic cells rescue vision in a rodent model of retinal degeneration. Exp Eye Res. 2010;91:449-55.

68. Hambright D, Park KY, Brooks M, McKay R, Swaroop A, Nasonkin IO. Long-term survival and differentiation of retinal neurons derived from human embryonic stem cell lines in un-immunosuppressed mouse retina. Mol Vis. 2012;18:920-36.

69. Lu B, Lin Y, Tsai Y, Girman S, Adamus G, Jones MK, et al. A subsequent human neural progenitor transplant into the degenerate retina does not compromise initial graft survival or therapeutic efficacy. Transl Vis Sci Technol. 2015:4:7.

70. Tsai Y, Lu B, Bakondi B, Girman S, Sahabian A, Sareen D, et al. Human iPSC-derived neural progenitors preserve vision in an AMD-like model. Stem Cells. 2015. doi:10.1002/stem.2032.

71. Jiang $C$, Klassen $H$, Zhang $X$, Young M. Laser injury promotes migration and integration of retinal progenitor cells into host retina. Mol Vis. 2010;16:983-90.

72. De Schaepdrijver L, Simoens P, Lauwers H, De Geest JP. Retinal vascular patterns in domestic animals. Res Vet Sci. 1989;47:34-42.

73. Sun J, Mandai M, Kamao H, Hashiguchi T, Shikamura M, Kawamata S, et al. Protective effects of human iPS-derived retinal pigmented epithelial cells in comparison with human mesenchymal stromal cells and human neural stem cells on the degenerating retina in rd1 mice. Stem Cells. 2015;33:1543-53.

74. Lakowski J, Gonzalez-Cordero A, West EL, Han YT, Welby E, Naeem A, et al. Transplantation of photoreceptor precursors isolated via a cell surface biomarker panel from embryonic stem cell-derived self-forming retina. Stem Cells. 2015. doi:10.1002/stem.2051.

75. Hu Y, Liu L, Lu B, Zhu D, Ribeiro R, Diniz B, et al. A novel approach for subretinal implantation of ultrathin substrates containing stem cell-derived retinal pigment epithelium monolayer. Ophthalmic Res. 2012;48:186-91.

76. Kundu J, Michaelson A, Baranov P, Young MJ, Carrier RL. Approaches to cell delivery: substrates and scaffolds for cell therapy. Dev Ophthalmol. 2014;53:143-54.

77. Singhal S, Lawrence JM, Bhatia B, Ellis JS, Kwan AS, MacNeil A, et al. Chondroitin sulfate proteoglycans and microglia prevent migration and integration of grafted müller stem cells into degenerating retina. Stem Cells. 2008;26:1074-82

78. Bull ND, Limb GA, Martin KR. Human Muller stem cell (MIO-M1) transplantation in a rat model of glaucoma: survival, differentiation, and integration. Invest Ophth Vis Sci. 2008:49:3449-56.

79. Dick AD, Ford AL, Forrester JV, Sedgwick JD. Flow cytometric identification of a minority population of $\mathrm{MHC}$ class II positive cells in the normal rat retina distinct from CD45lowCD11b/c + CD4low parenchymal microglia. Br J Ophthalmol. 1995;79:834-40.

80. Provis JM, Diaz CM, Penfold PL. Microglia in human retina: a heterogeneous population with distinct ontogenies. Perspect Dev Neurobiol. 1996;3:213-22.

81. Chen L, Yang P, Kijlstra A. Distribution, markers, and functions of retinal microglia. Ocul Immunol Inflamm. 2002;10:27-39.

82. Karlstetter M, Langmann T. Microglia in the aging retina. Adv Exp Med Biol. 2014:801:207-12

83. Nimmerjahn A. Resting microglial cells are highly dynamic surveillants of brain parenchyma in vivo. Science. 2005;308:1314-8.

84. Balasubramaniam B, Carter DA, Mayer EJ, Dick AD. Microglia derived IL-6 suppresses neurosphere generation from adult human retinal cell suspensions. Exp Eye Res. 2009;89:757-66. 
85. Karlstetter M, Ebert S, Langmann T. Microglia in the healthy and degenerating retina: insights from novel mouse models. Immunobiology. 2010;215:685-91.

86. Goodbrand IA, Gaze RM. Microglia in tadpoles of Xenopus laevis: normal distribution and the response to optic nerve injury. Anat Embryol (Berl). 1991;184:71-82.

87. Ng TF, Streilein JW. Light-induced migration of retinal microglia into the subretinal space. Invest Ophthalmol Vis Sci. 2001;42:3301-10.

88. Dick AD. Influence of microglia on retinal progenitor cell turnover and cell replacement. Eye. 2008;23:1939-45.

89. Hanisch U. Microglia as a source and target of cytokines. Glia. 2002;40:140-55

90. Ghasemi H, Ghazanfari T, Yaraee R, Owlia P, Hassan ZM, Faghihzadeh S. Roles of IL-10 in ocular inflammations: a review. Ocul Immunol Inflamm. 2012;20:406-18.

91. Sarra GM, Sarra FG, Schlichtenbrede FC, Trittibach P, Estermann S,

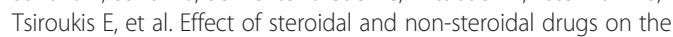
microglia activation pattern and the course of degeneration in the retinal degeneration slow mouse. Ophthal Res. 2005;37:72-82.

92. Ganter S, Northoff H, Mannel D, Gebicke-Harter PJ. Growth control of cultured microglia. J Neurosci Res. 1992;33:218-30.

93. Singhal S, Lawrence JM, Salt TE, Khaw PT, Limb GA. Triamcinolone attenuates macrophage/microglia accumulation associated with NMDAinduced RGC death and facilitates survival of Müller stem cell grafts. Exp Eye Res. 2010;90:308-15.

94. Jun CD, Hoon-Ryu, Um JY, Kim TY, Kim JM, Kang SS, et al. Involvement of protein kinase $C$ in the inhibition of nitric oxide production from murine microglial cells by glucocorticoid. Biochem Biophys Res Commun. 1994;199:633-8.

95. Chao CC, Hu S, Close K, Choi CS, Molitor TW, Novick WJ, et al. Cytokine release from microglia: differential inhibition by pentoxifylline and dexamethasone. J Infect Dis. 1992;166:847-53.

96. Piani D, Fontana A. Involvement of the cystine transport system xc- in the macrophage-induced glutamate-dependent cytotoxicity to neurons. J Immunol. 1994;152:3578-85.

97. Meng XL, Yang JY, Chen GL, Zhang LJ, Wang LH, Li J, et al. RV09, a novel resveratrol analogue, inhibits NO and TNF-a production by LPS-activated microglia. Int Immunopharmacol. 2008:8:1074-82.

98. Zhao L, Ma W, Fariss RN, Wong WT. Minocycline attenuates photoreceptor degeneration in a mouse model of subretinal hemorrhage. Am J Pathol. 2011;179:1265-77.

99. Wang AL, Yu AC, Lau LT, Lee C, Wu LM, Zhu X, et al. Minocycline inhibits LPS-induced retinal microglia activation. Neurochem Int. 2005;47:152-8.

100. Zhang C. Neuroprotection of photoreceptors by minocycline in lightinduced retinal degeneration. Invest Ophth Vis Sci. 2004;45:2753-9.

101. Sun C, Li X, He X, Zhang Q, Tao Y. Neuroprotective effect of minocycline in a rat model of branch retinal vein occlusion. Exp Eye Res. 2013;113:105-16.

102. Yang LP, Li Y, Zhu XA, Tso MO. Minocycline delayed photoreceptor death in rds mice through iNOS-dependent mechanism. Mol Vis. 2007;13:1073-82.

103. Chen M, Ona VO, Li M, Ferrante RJ, Fink KB, Zhu S, et al. Minocycline inhibits caspase- 1 and caspase- 3 expression and delays mortality in a transgenic mouse model of Huntington disease. Nat Med. 2000;6:797-801.

104. Zhu S, Stavrovskaya IG, Drozda M, Kim BY, Ona V, Li M, et al. Minocycline inhibits cytochrome $\mathrm{c}$ release and delays progression of amyotrophic lateral sclerosis in mice. Nature. 2002;417:74-8.

105. Liu X, Su H, Chu T, Guo A, Wu W. Minocycline inhibited the pro-apoptotic effect of microglia on neural progenitor cells and protected their neuronal differentiation in vitro. Neurosci Lett. 2013;542:30-6.

106. Skardelly M, Glien A, Groba C, Schlichting N, Kamprad M, Meixensberger J, et al. The influence of immunosuppressive drugs on neural stem/progenitor cell fate in vitro. Exp Cell Res. 2013;319:3170-81.

107. Rota NL, Ferrari D, Giani F, Bossi M, Rodriguez-Menendez V, Tredici G, et al. Long-term survival of human neural stem cells in the ischemic rat brain upon transient immunosuppression. PLoS One. 2010;5:e14035.

108. Suzuki T, Akimoto M, Imai H, Ueda Y, Mandai M, Yoshimura N, et al. Chondroitinase $A B C$ treatment enhances synaptogenesis between transplant and host neurons in model of retinal degeneration. Cell Transplant. 2007;16:493-503.

109. Rhodes KE, Fawcett JW. Chondroitin sulphate proteoglycans: preventing plasticity or protecting the CNS? J Anat. 2004;204:33-48.
110. Pearl Jl, Lee AS, Leveson-Gower DB, Sun N, Ghosh Z, Lan F, et al. Short-term immunosuppression promotes engraftment of embryonic and induced pluripotent stem cells. Cell Stem Cell. 2011;8:309-17.

111. Rong Z, Wang M, Hu Z, Stradner M, Zhu S, Kong H, et al. An effective approach to prevent immune rejection of human ESC-derived allografts. Cell Stem Cell. 2014;14:121-30.

112. Guo Y, Saloupis P, Shaw SJ, Rickman DW. Engraftment of adult neural progenitor cells transplanted to rat retina injured by transient ischemia. Invest Ophthalmol Vis Sci. 2003;44:3194-201.

113. Nishida A, Takahashi M, Tanihara H, Nakano I, Takahashi JB, Mizoguchi A, et al. Incorporation and differentiation of hippocampus-derived neural stem cells transplanted in injured adult rat retina. Invest Ophthalmol Vis Sci. 2000;41:4268-74

114. Sakaguchi DS, Van Hoffelen SJ, Young MJ. Differentiation and morphological integration of neural progenitor cells transplanted into the developing mammalian eye. Ann N Y Acad Sci. 2003;995:127-39. 